\title{
De buurtsportcoach: zinvolle partner van een integrale aanpak van gezondheidsbevordering
}

\author{
Annemarie Wagemakers · Gerard Molleman
}

Geaccepteerd op: 25 mei 2021

(C) The Author(s) 2021

In dit themanummer staan de functie en de impact van de buurtsportcoach centraal. In de afgelopen veertien jaar is hard gewerkt aan de functie buurtsportcoach, het bouwen van een lokale infrastructuur rond sport en bewegen, en het stimuleren van het gaan en blijven bewegen van mensen. In de periode vanaf 2007 heeft de buurtsportcoach zich met behulp van tijdelijke subsidieregelingen ontwikkeld van een combinatiefunctionaris gericht op jeugd en jongeren vaak met een bal onder de arm -, tot een buurtsportcoach die zich ook richt op volwassenen. Buurtsportcoaches dragen bij aan de lokale integrale infrastructuur ter bevordering van bewegen door het bouwen en coördineren van samenwerking en activiteiten met verschillende sectoren, zoals sport en bewegen, welzijn, onderwijs, zorg en cultuur. Dit kan echter nog beter benut worden: de potentie van buurtsportcoaches is groot, ook voor gezondheidsbevordering in het algemeen. In vrijwel alle Nederlandse gemeenten zijn buurtsportcoaches aan het werk.

Het bouwen van lokale infrastructuren voor preventie en gezondheidsbevordering staat op nationaal en lokaal niveau hoog op de agenda. Nota's van de Sociaal Economische Raad, de academische ziekenhuizen (NFU) en gemeentelijke preventie- en sportakkoorden pleiten voor een stevige en structurele inzet op preventie [1-3]. Ook zien we pleidooien voor meer preventie in de contourennota Zorg voor de Toekomst van VWS, een pleidooi van drie zorgverzekeraars, Zil-

\footnotetext{
A. Wagemakers $(\bowtie)$

Social Sciences, Gezondheid en Maatschappij, WUR,

Wageningen, Nederland

annemarie.wagemakers@wur.nl

G. Molleman

Radboud Institute for Health Sciences, Afdeling

Eerstelijnsgeneeskunde, Academische werkplaats AMPHI,

Radboudumc, Nijmegen, Nederland
}

veren Kruis, CZ en Menzis, en het rapport van de Raad voor Volksgezondheid en Samenleving 'Een eerlijke kans op gezond leven' [4-6]. Voor het bouwen en onderhouden van een structurele lokale preventieve infrastructuur waar idealiter naast publieke gezondheid ook welzijn, maatschappelijk werk en de beweegen sportsector onderdeel van zijn, hebben gemeenten echter structurele financiering nodig $[1,5,6]$. Als het over bewegen gaat is daarvoor met het landelijk dekkende netwerk van buurtsportcoaches al een belangrijke hoeksteen gerealiseerd.

De buurtsportcoach speelt ook een rol in het mogelijk maken van de Gecombineerde Leefstijlinterventie (GLI). De zorggerelateerde onderdelen worden sinds 2019 voor erkende interventies vergoed vanuit de Zorgverzekeringswet (Zvw). Het beweegdeel valt niet onder de Zvw, zodat mensen het zelf moeten betalen als de gemeente en/of een zorgverzekeraar dat niet doen, wat voor mensen met een lage sociaaleconomische positie problematisch kan zijn [7, 8]. Tegelijkertijd doen minder mensen dan verwacht mee aan een GLI omdat deze vaak nog (te) los staat van de lokale integrale aanpak. Buurtsportcoaches kunnen - meer dan nu gebeurt - hieraan bijdragen.

Dit themanummer laat zien dat de buurtsportcoach succesvol is in het verbinden van sectoren en in het bereiken van doelgroepen. De drie Forum-bijdragen laten zien hoe het succes van de buurtsportcoach tot stand is gekomen.

In de bijdrage van de Vereniging Sport en Gemeenten beschrijven André de Jeu en Marion Stroet de verschillende regelingen rond de combinatiefuncties en buurtsportcoach. Ze lichten ook de succesfactoren toe: werken vanuit vertrouwen, maatwerk en continuïteit. Marloes Aalbers schrijft vanuit het Kenniscentrum Sport \& Bewegen (KCS) hoe het beroep buurtsportcoach is veranderd en hoe dit tot de ontwikkeling van een beroepsgroep en een nieuw functiepro- 
fiel leidt. De auteurs van het Mulier Instituut, Wikke van Stam en Ine Pulles, sluiten hierbij aan en rapporteren over de diversiteit van de werkzaamheden van buurtsportcoaches en hun bijdrage - met enthousiasme en daadkracht - aan de uitvoering van het Nationaal Sportakkoord en Preventieakkoord.

De drie wetenschappelijke artikelen geven inzicht in de opbrengsten van de inzet van de buurtsportcoach en de evaluatie ervan. Karlijn Leenaars en coauteurs van de Wageningen Universiteit beschrijven welke verbindingen door de inzet van de buurtsportcoach gerealiseerd zijn en hoe deze samenhangen met de lokale inbedding van de buurtsportcoach. Eva Smit en coauteurs van het Radboudumc tonen aan dat het uitmaakt welke wervingsstrategie de buurtsportcoach gebruikt, en dat een actieve wervingsstrategie bijdraagt aan het aantrekken van de meest kwetsbare deelnemers. Tot slot bespreken Ad Hoogendam en Caroline van Lindert, beiden onderzoeker bij het $\mathrm{Mu}-$ lier Instituut, hoe de implementatie van een complex programma - zoals de lokale implementatie van de Brede Impuls Combinatiefuncties - het beste geëvalueerd kan worden.

Dit themanummer is mogelijk gemaakt door het door ZonMw gefinancierde project over de buurtsportcoaches (projectnummer 525001002). Dit project bestaat uit twee promotieonderzoeken, die zijn uitgevoerd door de Wageningen Universiteit en het Radboudumc [9, 10].

Onze dank gaat uit naar alle buurtsportcoaches, auteurs, reviewers en anderen die hebben bijgedragen aan dit themanummer. We wensen $\mathrm{u}$, de lezer, plezier met lezen en inspiratie toe voor een gezonder Nederland.

Open Access This article is licensed under a Creative Commons Attribution 4.0 International License, which permits use, sharing, adaptation, distribution and reproduction in any medium or format, as long as you give appropriate credit to the original author(s) and the source, provide a link to the Creative Commons licence, and indicate if changes were made. The images or other third party material in this article are included in the article's Creative Commons licence, unless indicated otherwise in a credit line to the material. If material is not included in the article's Creative Commons licence and your intended use is not permitted by statutory regulation or exceeds the permitted use, you will need to obtain permission directly from the copyright holder. To view a copy of this licence, visit http://creativecommons.org/licenses/by/4.0/.

\section{Literatuur}

1. Sociaal Economische Raad (SER). Zorg voor de toekomst; over de toekomstbestendigheid van de zorg. Den Haag: SER; 2020.

2. Nederlandse Federatie van UMC's (NFU). Toekomstbestendig zorgstelsel essentieel voor samenleving; aandachtspunten van de umc's voor een gezonder Nederland. Verkiezingsagenda NFU. Utrecht: Nederlandse Federatie van UMC's; 2020.

3. RIVM. Lokale en regionale preventieakkoorden; een beschrijving van lokale preventieakkoorden. Bilthoven: RIVM;2021.

4. Ministerie van Volksgezondheid, Welzijn en Sport. Discussienota 'Zorg voor de toekomst'. Den Haag: Ministerie van VWS; 2020.

5. Menzis, CZ,Zilveren Kruis. Samenwerken aan een gezonder Nederland en goede zorg voor iedereen. Enschede: Menzis, CZ, Zilveren Kruis; 2021.

6. Raad voor de Volksgezondheid en Samenleving (RVS). Een eerlijke kans op gezond leven. Den Haag: RVS; 2021.

7. Mulderij LS, Verkooijen KT, Koelen MA, et al. De werkzame elementen van een gecombineerdeleefstijlinterventie voor mensen met een lage sociaaleconomische status. Een concept mapping-caseonderzoek. Tijdschr Gezondheidswet. 2019;97:139-52.

8. Mulderij L, Verkooijen K, Wagemakers A. Gecombineerde leefstijlinterventies voor mensen meteenlageSES? Tijdschr Gezondheidswet. 2019;97(1):9-10.

9. SmitE, Leenaars KEF, Wagemakers MAE, etal. Evaluation of the role of care sport connectorsin connecting primary care, sport, and physical activity, and residents' participation in the Netherlands. Study protocol. BMC Publ Health. 2015;15:510.

10. Leenaars L. The care sport connector in the Netherlands [proefschrift]. Wageningen: Wageningen University; 2017. 